\title{
Paquimeningitis Hemorrágica Interna ¿Causa de muerte de Simón Bolívar?
}

\author{
David G. Martínez Neira ${ }^{1}$ \\ 1 Servicio de Neurocirugía, Hospital Luis Vernaza, Guayaquil - Ecuador.
}

¿Cómo saldré yo de este laberinto? Simón Bolívar

\section{Introducción}

Simón José Antonio de la Santísima Trinidad Bolívar Ponte Palacios y Blanco, libertador de Venezuela, Colombia, Ecuador y Perú, falleció en 1830, a los 47 años de edad. No existe consenso sobre la causa última de su muerte.

En 2011, Auwaerter ${ }^{1}$, luego de haber analizado el protocolo de la autopsia practicada por el Dr. Jean Próspero Revérend al cuerpo del General Bolívar, procedió a elaborar un listado de las posibles enfermedades. Estas fueron: tuberculosis, paracoccidiodomicosis, histoplasmosis, melioidosis, sífilis, bronquiectasia, arsenicosis, intoxicación por cantaridina, hemocromatosis, enfermedad de Wilson, diabetes mellitus, insuficiencia adrenal. Ese mismo año, el Gobierno de la República Bolivariana de Venezuela dispuso la exhumación de la osamenta de El Libertador.

En 2011, el Vicepresidente ejecutivo de Venezuela, Elías Jaua ${ }^{2}$, presentó en un acto público los resultados de los análisis realizados a los restos del prócer, indicó que no se pudo establecer que la muerte haya sido por causas no naturales o por envenenamiento intencionalmente provocado.

"No obstante queda abierta en la interpretación de la documentación la posibilidad de envenenamiento o intoxicación no intencional producto de la aplicación de tratamientos contaminados de arsénico o medicamentos arsenicales como la cantaridina"
A partir de la revisión del epistolario de Bolívar, del diario de su última enfermedad, y la descripción de los hallazgos de autopsia se plantea el diagnóstico de hematoma subdural crónico como la probable causa de muerte de El Libertador.

\section{Crónica}

Carta de Simón Bolívar al General Rafael Urdaneta ${ }^{3}$

Quinta Soledad, Turbaco, Colombia Noviembre 6 de 1830

"Mi mal se va complicando, y mi flaqueza es tal que hoy mismo me he dado una caída formidable, cayendo de mis propios pies, sin saber como, y medio muerto. Por fortuna no fue mas que un buen vahído que me dejó aturdido, mas eso siempre prueba lo que dije antes, que estoy muy débil".

Reporte del Dr. Jean Próspero Reverend sobre la condión del General Bolívar a su arribo Santa Marta

Diciembre 1 de 1830

"Su Excelencia llegó a esta ciudad de Santa Marta a las siete y media de la noche, procedente de Sabanilla en el bergantín nacional Manuel y habiendo venido a tierra en una silla de brazos por no poder caminar, le encontré en el estado siguiente: cuerpo muy flaco y extenuado, el semblante adolorido y una inquietud de ánimo constante. La voz ronca, una tos profunda con esputos viscosos y de color verdoso. El pul-

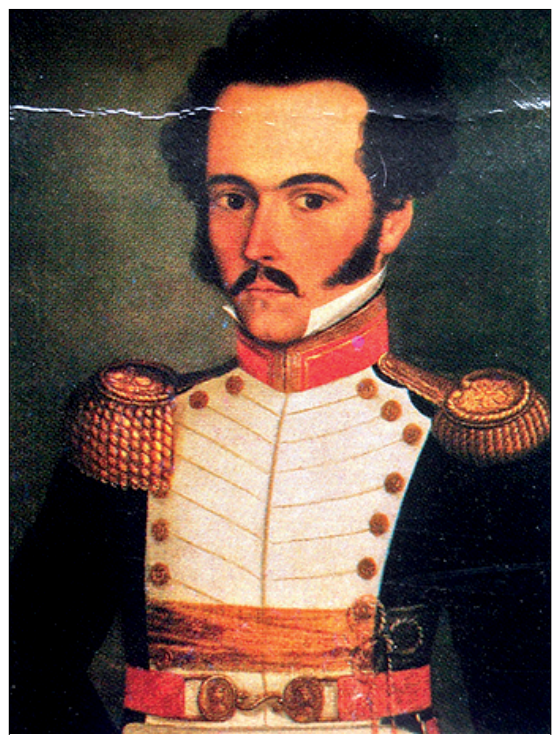

Figura 1. Simón Bolívar a los 26 años. Anónimo. Circa 1812. Óleo sobre tela. $27 \times 23 \mathrm{~cm}$. Casa Museo Quinta de Bolívar, Bogotá, Colombia.

so igual pero comprimido. La digestión laboriosa. Las frecuentes impresiones del paciente indicaban padecimientos morales. Finalmente, la enfermedad de Su Excelencia me pareció de las mas graves y mi primera opinión fue que tenía los pulmones dañados.."

Diario sobre la enfermedad que aflige a El Libertador, sus progresos o disminuciones y método curativo, Alejandro Próspero Revérend ${ }^{4}$ (resumen)

Santa Marta, Quinta San Pedro Alejandrino

Diciembre 1 al 17 de 1830 
Autopsia del cadáver del Excelentísimo Señor Libertador General Simón Bolívar, Dr. Alejandro Próspero Reverend5.

Santa Marta, Quinta San Pedro Alejandrino

Diciembre 17 de 1830, cuatro de la tarde

En presencia de los Señores Generales Beneméritos Mariano Montilla y José Laurencio Silva.

\section{Cabeza}

Los vasos de la aracnoides en su mitad posterior ligeramente inyectados, las desigualdades y circunvoluciones del cerebro recubiertas de una materia parduzca de consistencia y transparencia gelatinosa, un poco de serosidad semi roja bajo la duramater, el resto del cerebro y cerebelo no ofrecieron en su sustancia ningún signo patológico.

\section{Análisis}

Luego de un viaje agotador desde Bogotá al Caribe, en una primera etapa a caballo, y después por el Río Magdalena, el General Bolívar buscó recuperar fuerzas para continuar camino. Según sus propias palabras, sufrió una caída "formidable" desde su propia altura en noviembre 6 , habiendo quedado aturdido. Tres semanas y media después, ya no es capaz de caminar, por lo que se lo transporta en silla de brazos. Los Drs. Reverend y Night concordaron en el diagnóstico de "catarro pulmonar crónico". En los días subsiguientes predominó un cuadro neurológico al que Reverend calificó como "congestión en el cerebro", caracterizado por entorpecimiento de las facultades intelectuales, modorra (somnolencia muy pesada), e hipo constante. Pasó luego a un estado de coma vigil, con incontinencia urinaria, y murió en diciembre 17.

Los análisis de ADN mitocondrial realizados en el 2010 confirmaron que la osamenta exhumada en efecto era la del General Bolívar.

En el informe de autopsia, Reverend señala la presencia de una colección serohemática subdural y una materia (membrana) parduzca de consistencia y transparencia gelatinosa que recubría las circunvoluciones del cerebro. No hubo signos patológicos en el resto del cerebro y cerebelo.

Dado el antecedente de trauma por caída, y que 25 días después cursa un cuadro clínico caracterizado por dete-

\begin{tabular}{|c|c|c|}
\hline Boletín & Fecha & Observación \\
\hline 1 & Dic. 1 & Traído en silla de brazos por no poder caminar \\
\hline 2 & Dic. 2 & $\begin{array}{l}\text { Esputos color verdoso. El Dr. M. Night, cirujano de la goleta } \\
\text { de Guerra "Grampus" de los Estados Unidos, concordó } \\
\text { con la opinión que la enfermedad era un catarro pulmonar } \\
\text { crónico }\end{array}$ \\
\hline 3 & Dic. 3 & Desvelado y como con pequeños desvaríos \\
\hline 4 & Dic. 4 & Esta mañana hubo vómitos \\
\hline 5 & Dic. 5 & Dolor de pecho, también un poco de hipo \\
\hline 6 & Dic. 6 & El dolor de pecho había desaparecido \\
\hline 7 & Dic. 7 & Poca cantidad de esputos, es el mejor día que ha tenido \\
\hline 8 & Dic. 8 & $\begin{array}{l}\text { Amodorrado, le entró el hipo con más tesón, sensible en } \\
\text { torpecimiento de sus facultades intelectuales, "congestión } \\
\text { en el cerebro" }\end{array}$ \\
\hline 9 & Dic. 9 & $\begin{array}{l}\text { El hipo repitió con bastante fuerza. Cuando se le pregun- } \\
\text { taba si tenía algún dolor, siempre contestaba que no, por } \\
\text { lo que se conocía que el sistema nervioso estaba atacado }\end{array}$ \\
\hline 10 & Dic. 9 & $\begin{array}{l}\text { La misma modorra, la lengua ha estado algo trabajosa por } \\
\text { ratos, de noche se le notó delirio }\end{array}$ \\
\hline 11 & Dic. 10 & Desvelado, conversando solo y por consiguiente deliraba \\
\hline 12 & Dic. 10 & $\begin{array}{l}\text { La misma modorra, pero al despertarse hablaba con se- } \\
\text { renidad y claridad, sin embargo, aparecían los síntomas } \\
\text { de congestión en el cerebro }\end{array}$ \\
\hline 13 & Dic. 11 & $\begin{array}{l}\text { Amaneció con menos sopor, sin embargo la noche fue } \\
\text { molesta y con algún delirio. El hipo no fue tan tenaz }\end{array}$ \\
\hline 14 & Dic. 11 & $\begin{array}{l}\text { Los ataques de hipo no fueron tan fuertes, ni tan frecuen- } \\
\text { tes. Pequeño delirio }\end{array}$ \\
\hline 15 & Dic. 12 & Desvariando a menudo. Orines involuntarios \\
\hline 16 & Dic. 12 & Ideas algo confusas \\
\hline 17 & Dic. 13 & Orines involuntarios frecuentes \\
\hline 18 & Dic. 13 & $\begin{array}{l}\text { La misma confusión de ideas y aberración de la memoria } \\
\text { Las sensaciones están entorpecidas }\end{array}$ \\
\hline 19 & Dic. 14 & $\begin{array}{l}\text { Sigue el entorpecimiento en las sensaciones. Hay siempre } \\
\text { incontinencia de orina }\end{array}$ \\
\hline $20 / 21$ & Dic. 14 & Sopor casi continuo, coma vigil \\
\hline $22 / 23$ & Dic. 14 & Sopor permanece, el hipo no ha sido tan a menudo \\
\hline 24 & Dic. 15 & Casi lo mismo \\
\hline $25 / 26 / 27$ & Dic. 15 & El mismo desvarío, palabras balbuceantes, hipo a menudo \\
\hline $28 / 29$ & Dic. 16 & Hipo, pulso miserable, se sostiene la vida \\
\hline $30 / 31$ & Dic. 16 & $\begin{array}{l}\text { Lucha extrema de la vida con la muerte. Respiración } \\
\text { trabajosa }\end{array}$ \\
\hline 32 & Dic. 17 & La muerte está próxima \\
\hline 33 & Dic. 17 & $\begin{array}{l}\text { A las doce empezó el ronquido, y a la una en punto expiró } \\
\text { el Excelentísimo Señor Libertador }\end{array}$ \\
\hline
\end{tabular}

rioro neurológico progresivo, junto a un informe de autopsia que señala la presencia de hiperemia capilar y colección sero hemática subdural con materia parduzca no purulenta, parece razonable colegir el diagnóstico principal de hematoma subdural crónico, que ocasiona hipertensión intracraneal; 


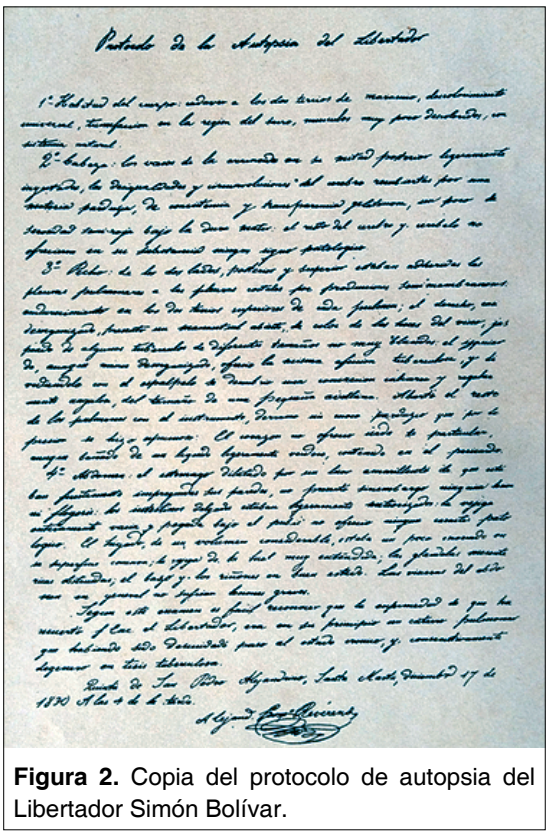

complicada su condición general con neumonía.

\section{Discusión}

De la lectura de los boletines se des- prende que Alejandro Próspero Reverend fue un médico competente en semiología neurológica; preparado por Laennec y Dupytren es evidente su pericia en anatomía patológica. Empleó el estilo descriptivo médico de la época para asentar sus observaciones, tal es el caso de "congestión del cerebro" término acuñado en 1751 por Morgag$\mathrm{ni}^{6}$, y que guarda relación con la apoplejía serosa o hematencéfalo. Esta nosología fue usada por 150 años, es así como al decir de Charcot?, "pues, o existe un delirio más o menos intenso (congestión meníngea), o bien existe por el contrario, un coma, más o menos profundo (congestión apopletiforme). En ambos casos hay postración de fuerzas".

El hipo intratable ha sido reportado en pacientes con hematoma subdural ${ }^{8}$, no deja de llamar la atención este síntoma que Bolívar presentó en forma persistente.

Lo descrito por Revérend en la autopsia practicada evoca lo que en 1857 Virchow $^{9}$ denominó pachymeningitis haemorrhagica, entidad señalada por Rindfleish ${ }^{10}$ en su libro de texto en 1872. La etiología traumática fue sugerida en el reporte de Trotter ${ }^{11}$ que data de 1914. Diez años después, Putnam y Cushing ${ }^{12}$ delinearon el método curativo, de este tipo de lesión que a partir de inicios del siglo $X X$ se conoce como hematoma subdural, patología que sigue siendo motivo de revisión en el siglo $X X{ }^{13}$.

\section{Colofón}

En aquella ciudadela de su última enfermedad, donde fue llevado en peso, Simón Bolívar transitó ceñido por la tos, los desvaríos, agobiado por un persistente hipo y al final empapado en orina. Desde 1830 se han sucedido cerrados callejones diagnósticos que van desde la tuberculosis hasta el envenenamientos por arsénico. Sabía El Libertador que: "Tal es el espíritu humano, amigo y entusiasta de lo sobre natural y de la mentira; indiferente sobre las cosas naturales y la verdad". Ya eran las doce de la noche que tocaron en el relox del Libertador, y entonces S.E. dijo: "bastante hemos filosofado, vamos a dormir"14.

Confío en que estos párrafos, de alguna forma, permitan al General salir de este laberinto.

\section{Recibido: 23 de febrero de 2016 Aceptado: 04 de marzo de 2016}

\section{Bibliografía}

1. Auwaerter P, Mackosiak P. Simon Bolivar's Medical Labyrinth: an infectious diseases conundrum. Clin. Infect. Dis. $2011 ; 52: 78-85$.

2. Restos de Bolívar son auténticos, las causas de su muerte siguen sin cerrarse. La información.com, 2011, Julio 25. Descargado Enero 6, 2015 www.lainformacion.com

3. Bolívar S. (1947) Carta al General Rafael Urdaneta. Soledad, 6 de Noviembre de 1830. Obras Completas, Tomo II 954 - 956 Editor, Vicente Lecuna, La Habana, Cuba, Editorial Lex.

4. Revérend AP. (1866) La última enfermedad, los últimos momentos y los funerales de Simón Bolívar, Libertador de Colombia y del Perú, por su médico de cabecera. París, Francia: Imprenta Hispano-Americana de Cosson y Comp.

5. Revérend AP. Copia del Protocolo de Autopsia 1830. Correa Pelayo, Arias-Stella Javier, Pérez Tamayo Ruy, Carbonell M. Luis (1970), Texto de Patología, México DF, México. La Prensa Médica Mexicana.

6. Román GC. Cerebral congestion. A vanished disease. Arch. Neurol. 1987; 44: 444-448.

7 Charcot JM. Flores y Pla M. (1882) Lecciones sobre las Enfermedades del Sistema Nervioso dadas en la Salpêtrière, coleccionadas y publicadas por Bourneville, Tomo Primero pp 418 - 419. Madrid, España. Imprenta de A. Pérez Dubrul.

8 Gjerris F, Schmidt K. Chronic subdural hematoma, Surgery or mannitol treatment. J. Neurosurg. 1974; 40: 639-642.

9 Virchow. Das Hämatom der Duramater. Verh.phys.-med.ges.Würzburg, 1857, 7: 134.

10 Rindfleish E. (1872) A textbook of pathological histology: an introduction to the study of pathological anatomy, translated from the second German Edition by William C. Kloman. Pp 619 - 620 Philadelphia, U.S.A. Lindsay \& Blakiston.

11 Trotter W. Chronic subdural haemorrhage of traumatic origin, and its relation to pachymeningitis haemorrhagica interna. Brit. J. Surg., 1914, 2: 271-291.

12 Putnam TJ, and Cusshing $\mathrm{H}$. Chronic subdural hematoma. Its pathology, its relation to pachymeningitis hemorrhagica and its surgical treatment. Arch. Surg. Chicago, 1925;11: 329-393.

13 Kolias A, Chari A, Santarius T, Hutchinson P. Chronic subdural hematoma: modern management and emerging therapies. Nat. Rew. Neuro., 2014; 10: 570-578.

14 Perú de la Croix L. Diario de Bucaramanga, pp 257 Caracas, Venezuela. www.minci.gob.ve / Descargado Enero 6, 2015.

Correspondencia a:

Dr. David Martínez Neira

Hospital Luis Vernaza - Guayaquil- Ecuador

davidmartinezneira@gmail.com 